\title{
A DINÂMICA DE ANALISAR LIVROS DIDÁTICOS COM OS PROFESSORES DE QUÍMICA
}

\author{
Rochele de Quadros Loguercio \\ Instituto de Ciências Básicas da Saúde/Instituto de Química, Universidade Federal do Rio Grande do Sul, Av. Bento Gonçalves, \\ 9500, 91501-970 Porto Alegre - RS \\ Vander Edier Ebling Samrsla e José Claudio Del Pino* \\ Instituto de Química, Universidade Federal do Rio Grande do Sul, Av. Bento Gonçalves, 9500, 91501-970 Porto Alegre - RS
}

Recebido em 1/2/00; aceito em 15/12/00

\begin{abstract}
THE DYNAMICS OF ANALYZING TEXT BOOKS WITH CHEMISTRY TEACHERS. This work evidences a survey conducted during a teacher professional qualification in Rio Grande do Sul, Brazil. This survey analysed the textbooks used by these teachers. The dynamics consisted of choosing the analytic criteria used by teachers, and adding new criteria for examining their difficulties and ways to choose textbooks. This article emphasises the problematics and difficulties teachers have to make choices and their loss of skills and authority to consider these books more profoundly.
\end{abstract}

Keywords: textbooks; chemical education; teacher formation.

\section{INTRODUÇÃO}

As relações entre os livros didáticos em Química e as produções curriculares nas escolas são temáticas constantes em diversos artigos, dissertações e livros. As análises referem-se a aspectos tão diversificados como a produção, a comercialização, a inserção do conhecimento na evolução histórica, a qualidade gráfica e a adequação dos conteúdos. Trabalhos como os de Alice Lopes ${ }^{1}$ e Roseli Schnetzler ${ }^{2}$ evidenciam alguns aspectos fundamentais da construção do conhecimento químico e a própria noção da epistemologia da ciência que estes livros didáticos podem produzir. Estudos como os de Paulo Vaz (em Guerra ${ }^{3}$ e Olga Molina ${ }^{4}$ justapõem as questões de conhecimento ao cuidado com o visual e com a diagramação dos livros como facilitadores ou não da compreensão dos conteúdos. Em outras perspectivas de análise, são realizadas investigações através das questões sociais e políticas, dentre essas se pode citar os textos de Michael Apple ${ }^{5}$, que fazem leituras das questões de gênero, classe e raça presentes nos livros e, ainda, a ligação dessas temáticas com a produção e a organização interna das editoras. Como se pode perceber, existem inúmeras análises, nas mais diversas perspectivas teóricas e preocupadas com diferentes aspectos específicos dos livros didáticos. A partir delas, se têm condições de analisar os materiais didáticos que nos chegam às mãos, agregando novos critérios àqueles que já vinham sendo adotados.

Esse artigo é uma narrativa do contato de professores de Química do Rio Grande do Sul com um texto ${ }^{6}$ que sintetiza diversas das discussões acima citadas. É, também, a explicitação de uma dinâmica realizada com esses professores que repensou os livros didáticos de duas formas distintas: primeiro tornando explícitos os critérios utilizados por eles para escolher um livro didático, segundo trazendo a conhecer alguns critérios distintos produzidos nas academias e que poderiam tornar-se instrumentos de análise e reflexão para esses professores. A contribuição desse artigo é, portanto, evidenciar a análise de livros didáticos de Química realizada por professores e mostrar o quão importante e difícil pode ser a escolha desses livros para o quadro docente que percebe a dimensão e a influência dos livros didáticos na sua formação e no currículo ${ }^{7}$.

*e-mail: aeq@iq.ufrgs.br

\section{O CONTEXTO DA ANÁLISE}

Esta pesquisa foi realizada no estado do Rio Grande do Sul, ao longo dos cursos oferecidos pela Área de Educação Química da UFRGS e vinculados ao Projeto de Qualificação em Serviço dos Professores de Química do RS - PROCIÊNCIAS/ FAPERGS/CAPES. Estes cursos atingiram, em suas duas primeiras edições, 198 professores, que participaram de discussões que problematizavam os currículos, os conteúdos, as temáticas e as pedagogias relativas ao ensino de Química. Nessa jornada de discussões, houve espaço para problematizar os livros didáticos, sua "qualidade", seus usos, seus conceitos.

Esta problematização teve como referência teórica principal os trabalhos de Bachelard (através da leitura de Alice Lopes ${ }^{1}$ ) e contou com um texto de apoio, organizado pelos pesquisadores da Área de Educação Química ${ }^{6}$. O referido texto apresenta questões e exemplificações de quatro dos obstáculos epistemológicos elencados por Bachelard ${ }^{8}$ no seu livro Formação do Espírito Científico, de 1938, juntamente com outras problematizações, tais como discutir critérios de avaliação que punham de manifesto questões sociais, epistemológicas e gráficas que pudessem se somar aos critérios que os professores já utilizam para a escolha dos livros didáticos com os quais trabalham nas suas aulas. Procurou-se, através desta prática, perceber as dificuldades dos professores para analisar os livros didáticos e, também, colaborar para a inserção na escola de discussões relevantes e constituidoras sobre os livros, discussões essas que raramente ultrapassam os espaços acadêmicos ${ }^{9}$.

\section{QUESTÕES EM FOCO}

Dentre as diversas questões que surgiram durante os trabalhos, selecionou-se algumas para análise que enfocaram: a) os livros que os professores utilizam, conhecem ou trabalham; b) os critérios adotados pelos professores quando da escolha dos livros didáticos, e c) as análises de livros didáticos realizadas pelos professores, a partir dos critérios destacados pelo texto de apoio.

A primeira questão a ser analisada é quanto à presença dos livros didáticos em sala de aula. Em nossa população alvo, cerca de $30 \%$ dos professores em atividade no interior do estado do RS, adotam esses livros como livros-guia em suas salas de aula. Essa adoção é menor na capital do Estado, onde cerca de $16 \%$ utilizam os livros didáticos como livros-guia. ${ }^{10}$. Dian- 
te desse percentual e cientes de que os livros didáticos, mesmo sem adotá-los como livros-guia em sala de aula, são os recursos mais freqüentemente utilizados pelos professores para orientarem suas práticas ${ }^{2,11}$, procurou-se evidenciar de que modo estes livros são selecionados e quais são eles.

A seleção dos livros didáticos é, de acordo com os professores, baseada em vários critérios, dentre os quais se destacam a necessidade de relacionar os conteúdos com o cotidiano, com o vestibular e, preferencialmente, estarem compactadas essas informações em um volume único. Explicitando os critérios dos professores entende-se que o volume único atende às necessidades de baixar o custo e ser utilizado durante os 3 anos do ensino médio. A relação com o cotidiano é uma proposta assumida pelos autores e pelas grandes editoras a partir da década de 90, incluindo nos livros didáticos tradicionais exemplos e problemas comumente discutidos no dia a dia; enquanto que o conteúdo e as questões de vestibulares buscam suprir a necessidade daqueles alunos que tentam ingressar em uma universidade, uma proposta clara das editoras.

Diante desses critérios não foi surpreendente encontrar como livros didáticos tradicionais mais utilizados pelos professores os volumes únicos dos autores Ricardo Feltre ${ }^{12}$, Tito Peruzzo \& Eduardo Canto ${ }^{13}$ e Martha Reis ${ }^{14}$. Destaca-se que esses livros foram citados inclusive por professores, participantes dos cursos, e que não adotam livros didáticos como livros-guia.

Uma vez explicitados os livros didáticos mais conhecidos e utilizados pelos professores, bem como seus critérios de escolha mais comuns, propôs-se somar outros critérios aos já identificados com o intuito de possibilitar uma forma diferenciada de análise que poderia autorizá-los a pensar as propostas pedagógicas e os possíveis obstáculos epistemológicos eventualmente presentes nos livros didáticos ${ }^{12,13,14}$ que eles haviam selecionado como sendo os mais adequados aos seus critérios.

Antes de destacar alguns aspectos dessa análise, cabe evidenciar mais especificamente o contexto em que essa se fez e como foi gerenciada. Como já explicitado, essa foi uma dinâmica desenvolvida em um curso de formação continuada de professores que iniciou com a apresentação dos dados acima discutidos - critérios de escolhas de livros didáticos e livros mais utilizados e conhecidos pelos professores- e culminou com a análise dos professores de um livro escolhido por eles utilizando os novos critérios. Não houve, no entanto, uma determinação quantitativa nessa análise. Não há um critério que especifique o número de obstáculos epistemológicos ou a quantidade de páginas contendo poluição visual limite para se dizer que um livro é ruim ou bom. É claro que quanto menor o número de problemas identificados, melhor o trabalho com o livro, menor a necessidade de gerenciar e discutir esses problemas com os alunos e maior a tranquiilidade do professor para utilizar os textos.

Não houve, também, um controle do trabalho do professor em termos de identificar se ele analisou um capítulo, uma seção, uma temática especifica. $\mathrm{O}$ professor tinha autonomia para escolher a análise que considerasse mais adequada, qualificada e de acordo com o seu tempo e com o conhecimento do qual foi possível se apropriar. No entanto, alguns aspectos e critérios evidenciados no texto de apoio utilizado pelo professor exigiam que se analisasse o livro como um todo. É o caso dos aspectos gráficos, das questões relativas a apresentação de experiências e os aspectos sócios-políticos.

Os dados que são apresentados nas tabelas abaixo são decorrentes das análises feitas pelos professores dos três livros mais utilizados e/ou citados. Pode-se questionar a validade das análises, pode-se entender que são percentuais e, portanto, não refletem o pensamento de cada professor, mas o que está sendo mostrado é que de acordo com os professores os livros indicados têm essas características e que essa análise feita pelos professores é útil para se entender e investigar não só os livros didáticos, mas o próprio quadro docente que os analisou.
O resultado da análise dos livros didáticos de Química realizada pelos professores com os novos critérios, para efeito de sistematização nesse artigo, foi dividido em três partes que são apresentadas nas Tabelas 1, 2 e 3. A primeira refere-se a questões relativas aos aspectos gráficos, tais como se os livros possuem ou não ficha catalográfica e índice remissivo, a existência de uniformidade gráfica ao longo da obra, a qualidade da diagramação e da impressão e se a obra apresenta características que possam ser enquadradas no conceito de poluição visual ${ }^{15}$.

Tabela 1. Alguns aspectos gráficos observados pelos professores na análise de livros didáticos.

\begin{tabular}{|c|c|c|c|c|c|c|}
\hline & Martha & Reis & Ricardo & Feltre & Tito e & Canto \\
\hline & Sim & Não & Sim & Não & Sim & Não \\
\hline $\begin{array}{l}\text { Ficha } \\
\text { catalográfica* }\end{array}$ & $60 \%$ & $20 \%$ & $75 \%$ & $13 \%$ & $50 \%$ & $17 \%$ \\
\hline $\begin{array}{l}\text { Índice } \\
\text { remissivo*** }\end{array}$ & $10 \%$ & $60 \%$ & $13 \%$ & $75 \%$ & 0 & $50 \%$ \\
\hline $\begin{array}{l}\text { Uniformidade } \\
\text { gráfica }\end{array}$ & $100 \%$ & 0 & $100 \%$ & 0 & $100 \%$ & 0 \\
\hline Boa diagramação & $100 \%$ & 0 & $100 \%$ & 0 & $100 \%$ & 0 \\
\hline Boa impressão & $100 \%$ & 0 & $100 \%$ & 0 & $100 \%$ & 0 \\
\hline Poluição visual & $20 \%$ & $60 \%$ & $13 \%$ & $50 \%$ & $17 \%$ & $83 \%$ \\
\hline
\end{tabular}

Obs.: As percentagens não somam $100 \%$ porque nem todos os professores opinaram a respeito de todos os itens. * Os três livros analisados possuem fichas catalográficas. ** Os três livros analisados não possuem índice remissivo.

Tabela 2. Alguns obstáculos epistemológicos observados pelos professores na análise de livros didáticos.

\begin{tabular}{|c|c|c|c|c|c|c|}
\hline & Marthe & Reis & Ricardo & Feltre & Tito & Canto \\
\hline & Sim & Não & Sim & Não & Sim & Não \\
\hline $\begin{array}{l}\text { Obstáculos } \\
\text { animistas }\end{array}$ & $20 \%$ & $50 \%$ & $13 \%$ & $62 \%$ & $33 \%$ & $33 \%$ \\
\hline $\begin{array}{l}\text { Obstáculos } \\
\text { substancialistas }\end{array}$ & $30 \%$ & $40 \%$ & $50 \%$ & 0 & $33 \%$ & $33 \%$ \\
\hline $\begin{array}{l}\text { Obstáculos } \\
\text { realistas }\end{array}$ & $30 \%$ & $40 \%$ & $25 \%$ & $25 \%$ & $17 \%$ & $67 \%$ \\
\hline $\begin{array}{l}\text { Obstáculos } \\
\text { verbais }\end{array}$ & $20 \%$ & $50 \%$ & $25 \%$ & $25 \%$ & $17 \%$ & $50 \%$ \\
\hline
\end{tabular}

Obs.: A diferença de valores para completar $100 \%$ corresponde aos professores que não opinaram a respeito do item em questão.

Tabela 3. Análise realizada pelos professores sobre a natureza das experiências presentes nos livros didáticos.

\begin{tabular}{lcccccc}
\hline & \multicolumn{2}{c}{ Martha Reis } & \multicolumn{2}{c}{ Ricardo Feltre } & Tito e Canto \\
\hline & Sim & Não & Sim & Não & Sim & Não \\
\hline $\begin{array}{l}\text { Referência a } \\
\text { experiências }\end{array}$ & $80 \%$ & 0 & $50 \%$ & $50 \%$ & $50 \%$ & 0 \\
$\begin{array}{l}\text { São viáveis de } \\
\text { realização } \\
\text { na escola }\end{array}$ & $50 \%$ & 0 & $25 \%$ & $13 \%$ & $33 \%$ & $17 \%$ \\
$\begin{array}{l}\text { São perigosas } \\
\text { para os alunos } \\
\begin{array}{l}\text { São de natureza } \\
\text { investigativa }\end{array}\end{array}$ & $10 \%$ & $30 \%$ & $13 \%$ & $13 \%$ & 0 & $33 \%$ \\
\hline
\end{tabular}

Obs.: A diferença de valores para completar $100 \%$ corresponde aos professores que não opinaram a respeito do item em questão. 
O texto de apoio posto à disposição dos professores continha informações sobre as formas de análise empreendidas por especialistas na área dos itens poluição visual, diagramação, impressão e uniformidade gráfica. No entanto, não continha informações sobre índice remissivo e ficha catalográfica, pois nos parecia de fácil identificação, o que se mostrou uma premissa equivocada. Observando a tabela 1, nota-se que alguns professores têm dificuldades de identificar esses itens aparentemente simples.

Em outros aspectos, no entanto, houve um consenso de interpretação, pois $100 \%$ dos professores consideram boa a qualidade gráfica dos livros analisados, ainda que apontando alguns problemas de poluição visual.

$\mathrm{Na}$ tabela 2, estão registrados os aspectos da pesquisa relativos ao tratamento dos conteúdos, especialmente, os possíveis problemas com obstáculos epistemológicos. As características das experiências propostas e seu direcionamento aparecem na tabela 3 .

A análise relativa aos obstáculos epistemológicos, entendidos como entraves inerentes ao próprio conhecimento científico, que bloqueiam seu desenvolvimento e construção evidencia as dificuldades conceituais que muitas vezes limitam aos professores a análise dos livros. Para o entendimento destes obstáculos, tal como propõe Bachelard ${ }^{8}$, é necessário um conhecimento profundo da própria disciplina de química e, nesse caso, também da linguagem bachelardiana, à qual os professores não estão acostumados, seja por distanciamento dos centros acadêmicos, onde estas discussões comumente se dão, seja pela intensificação ${ }^{16}$ a que estão submetidos. Provavelmente devido a estes e a uma rede de outros fatores, os professores tiveram dificuldades de identificar os obstáculos epistemológi$\cos ^{17}$ nos livros analisados. Pode-se verificar, na tabela 2 , que em média $30 \%$ dos professores simplesmente não responderam a essas questões e, os demais, dividiram-se quanto à presença ou não destes obstáculos. Uma provável explicação para esta diferença entre os professores analistas, é a dificuldade de entender a lógica utilizada por Bachelard para identificar como obstáculos algumas questões que, por serem tão comuns, estão entendidas por esses professores como facilitadoras do conhecimento e não como entraves a esse. É possível inferir, também, que os próprios professores tenham se apropriado do conhecimento químico através desses obstáculos o que resultaria a impossibilidade de questioná-lo.

Uma análise mais profunda a respeito das experiências (atividades práticas) também não foi realizada por todos os professores, que se limitaram a observar nos livros se havia ou não referências às mesmas. Cabe destacar que no texto de apoio utilizado pelos professores a proposta de análise de experiências foi além da simples verificação da sua presença ou não nos livros didáticos. Os professores, ao fazerem sua análise, tinham autonomia de trabalho e, em sua maioria, não priorizaram a verificação das experiências no sentido de sua possibilidade de execução na realidade escolar do professor, bem como, a possibilidade de ocorrerem riscos à integridade física dos alunos ou não. A maneira como estas experiências são colocadas nos livros (de forma investigativa ou ilustrati$\mathrm{va}^{18}$ ) teve pouca ênfase nas suas análises. Pode-se supor que essa dificuldade de analisar experimentos, deve-se ao fato de que os professores não estão acostumados a realizar atividades práticas em suas aulas o que resulta num desinteresse sobre essas questões ${ }^{19}$. Outro problema está associado ao primeiro, o desinteresse pode ter origem na falta de conhecimento químico. Uma atividade prática, seja para ser realizada ou analisada, exige um maior entendimento químico por parte dos professores.

Os professores consideraram que os livros de Química analisados estão relacionados com o cotidiano dos alunos (Martha Reis - 60\%; Ricardo Feltre - 62\%; Tito e Canto - 83\%). Porém não houve uma preocupação em verificar se os "fatos do cotidiano" são usados como temas geradores para as práticas pedagógicas ou se são colocados apenas como exemplos, mantendo a abordagem tradicional ${ }^{19}$.
E, finalmente, passou-se a discutir especificamente os aspectos sócios-políticos presentes nestes livros e que faziam parte das problemáticas apresentadas no texto de apoio ${ }^{6}$, as questões de classe, gênero e raça que compunham um possível currículo oculto. Entende-se por currículo oculto aquelas questões que subjazem aos textos e ilustrações nos livros didáticos, onde podem aparecer questões sociais e políticas que por não estarem explícitas permitem a passagem de conceitos com os quais os próprios professores podem não concordar, mas que, sem perceber, promovem a sua multiplicação. Essa é exatamente a lógica do currículo oculto, por ser naturalizado na cultura não é visível.

$\mathrm{O}$ que se pode perceber das análises dos professores relativas a esta temática foi uma grande controvérsia. Essa controvérsia já era esperada, pois a percepção de alguns discursos depende do quanto o analista foi interpelado por esses discursos. Assim, o que para algumas pessoas pode ser considerado um currículo subjacente ao texto, com seus valores e idéias constituidores de noções sociais, para outros pode não ser perceptível.

Para exemplificar essa controvérsia citamos a inclusão das figura do negro e da mulher em alguns livros didáticos tradicionais analisados. Ao analisar os textos alguns professores imediatamente perceberam o pequeno número de ilustrações que representam os negros e questionaram a necessidade dessa presença num país com tamanha diversidade racial como o nosso. Já outros professores não perceberam este aspecto, assim como não perceberam também que, nas ilustrações desses livros, a maioria dos serviços realizados por mulheres são atividades domésticas. Ambos os exemplos mostram o que chamamos de conversão do olhar: é preciso perceber que os negros existem e têm possibilidades de realizar atividades e aparecerem em livros didáticos, bem como que as mulheres há muito tempo invadiram os laboratórios e o restante do mercado de trabalho, assim como os homens assumiram grande parte da atividade doméstica. As questões como já foi dito são polêmicas e é necessário ser interpelado por novos discursos para poder questionar o reconhecível que nesse caso é de que muitos negros não realizam atividades de maior status na sociedade e que muitas mulheres continuam em suas atividades domésticas. Os discursos que subjazem a essas ausências ou presenças são as visões político-sociais dos autores e editores desses livros com relação a negros e mulheres.

A importância dessa discussão é a de desnaturalizar o que é natural e, portanto, ao tornar estranho: tornar visível. O texto de apoio $^{6}$ trazia alguns exemplos de currículo oculto buscando causar estranheza aos professores, facilitando a apropriação dessa capacidade de desnaturalização.

\section{OUTROS TEXTOS}

Neste artigo, até aqui, discutiu-se livros de autores e editoras bastante conhecidos no mercado editorial, aos quais se convencionou chamar livros didáticos tradicionais. Porém, os professores também analisaram outros livros didáticos, produzidos por editoras universitárias e por grupos de pesquisadores, aos quais serão chamados de livros didáticos alternativos, que propõem algumas abordagens alternativas aos primeiros.

Como se pode verificar no gráfico 1, dos 198 professores com os quais se trabalhou, $40 \%$ não conheciam nenhuma proposta alternativa no ensino de química, $18 \%$ indicaram como propostas alguns livros alternativos, enquanto que $25 \%$ dos professores indicam outras propostas que são citadas como: construtivismo, ensino voltado para o cotidiano dos alunos, realização de experiências e utilização de técnicas e estratégias de ensino, mas que não estão especificamente relacionadas com publicações em livros alternativos para o ensino de Química.

Os livros didáticos alternativos citados pelos professores estão listados no gráfico 2. Ao analisar esse gráfico, é importante lembrar que se estava trabalhando com professores atuantes na rede de ensino do estado do Rio Grande do Sul, 
sendo esse um dos fatores determinantes de aparecerem, nas três primeiras indicações, os livros produzidos regionalmente: em primeiro lugar, Química I - Construção de Conceitos Fundamentais $^{20}$ de Otávio Aloísio Maldaner, produzido na Universidade de Ijuí; em segundo lugar, o item outros, onde são citados materiais didáticos produzidos pela Área de Educação Química $^{21}$, pelo Centro de Ciências do Rio Grande do Sul e pelo Colégio de Aplicação da UFRGS; e, em terceiro lugar, um projeto de pesquisa desenvolvido pela Área de Educação Química, junto aos professores da $28^{\mathrm{a}}$ Delegacia de Educação$\mathrm{RS}$, que gerou outro tipo de material didático em forma de polígrafos $^{22}$ para cada uma das três séries do ensino médio. Os demais livros indicados apresentam um percentual inferior a $6 \%$ dos professores.

Prosseguindo esse estudo, direcionou-se o trabalho para os $18 \%$ dos professores que conheciam alguns livros alternativos e, se verificou que $78 \%$ utilizavam esses materiais em sala de aula, total ou parcialmente. Esses professores relatam, em sua maioria $(86,7 \%)$, que obtiveram bons resultados ao trabalhar com estes livros, percebidos através da participação e da motivação gerada nos alunos.

Nosso grupo de pesquisa está efetivamente trabalhando com professores da rede pública do Rio Grande do Sul há cinco anos, esse tempo já foi suficiente para perceber o difícil acesso que os professores têm a esses livros. Frente ao número pequeno de professores que conhecem livros alternativos sempre se adotou a prática de levar esses textos para os cursos realizados. Desta forma, os 198 participantes dessa jornada de

\section{$\square$ Conhecem livros} alternativos $18 \%$

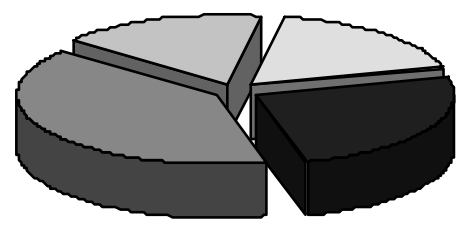

\section{$\square$ Conhecem outras propostas $25 \%$ $\square$ Não conhecem $40 \%$ \\ $\square$ Não responderam $17 \%$}

Gráfico 1. Respostas dadas pelos 198 professores de Química do RS à pergunta: "Você conhece propostas metodológicas elou pedagógicas alternativas de ensino de Química?" trabalho tiveram a oportunidade de conhecer alguns livros alternativos ${ }^{24}$ e escolher os livros para fazerem a sua análise. Essa escolha estava vinculada a algumas necessidades básicas: para o nosso grupo de pesquisa era importante que os livros fossem todos analisados e que não houvesse uma disparidade em favor de apenas alguns livros; para os professores a escolha estava imbricada com os momentos em sala de aula, dessa tensão entre as duas necessidades conduziram-se negociações que atendessem da melhor maneira possível aos dois grupos. Podemos afirmar que os livros foram divididos e analisados sem um vício de escolha que possa interferir nos resultados dos trabalhos aqui evidenciados. Assim cada um dos 198 professores leu e analisou um dos livros citados e sua análise utilizou os critérios novos, apresentados nos cursos, bem como, os critérios de viabilidade econômica, entre outros.

Nos livros alternativos, a análise não pode ser colocada em termos de qualidade gráfica da mesma forma que foi colocada para os livros tradicionais, pois as produções alternativas implicam alto custo, em função do pequeno número de exemplares. Nesses livros, os professores não encontraram problemas conceituais, obstáculos epistemológicos animistas e substancialistas, nem questões de raça, gênero e classe subjacentes ao livro, porém identificaram alguns obstáculos verbais e realistas. É importante destacar que ao identificar obstáculos epistemológicos é preciso ter no mínimo dois tipos de entendimento diferenciados: um conhecimento aprofundado de química e uma capacidade de conversão do olhar. Assim algumas opiniões dos professores são conflitantes como vimos na tabela 3. Desta forma não se pode dizer que inexistem esses elementos nos livros analisados, mas é evidente que os professores tiveram mais dificuldades para identificá-los.

Assim, pode-se dizer que os professores ao analisarem os livros alternativos percebem as suas desvantagens em termos de qualidade gráfica - o que não chega a comprometer o texto - e as suas vantagens em termos epistemológicos. Porém a grande dificuldade encontrada para a sua utilização é a sua especificidade. Existem, por parte dos professores analistas destes trabalhos, reclamações quanto à especificidade dos materiais didáticos alternativos e a dificuldade de direcioná-los às "necessidades" dos alunos que pretendem passar pelos concursos vestibulares.

Percebe-se que os professores analisaram estes livros de maneira mais ampla e, assim, obtiveram resultados semelhantes. Esses materiais enfocam o conhecimento químico de maneira muito distinta, alguns destacam as questões políticas, outros as questões ambientais e outros fazem uma sistematização

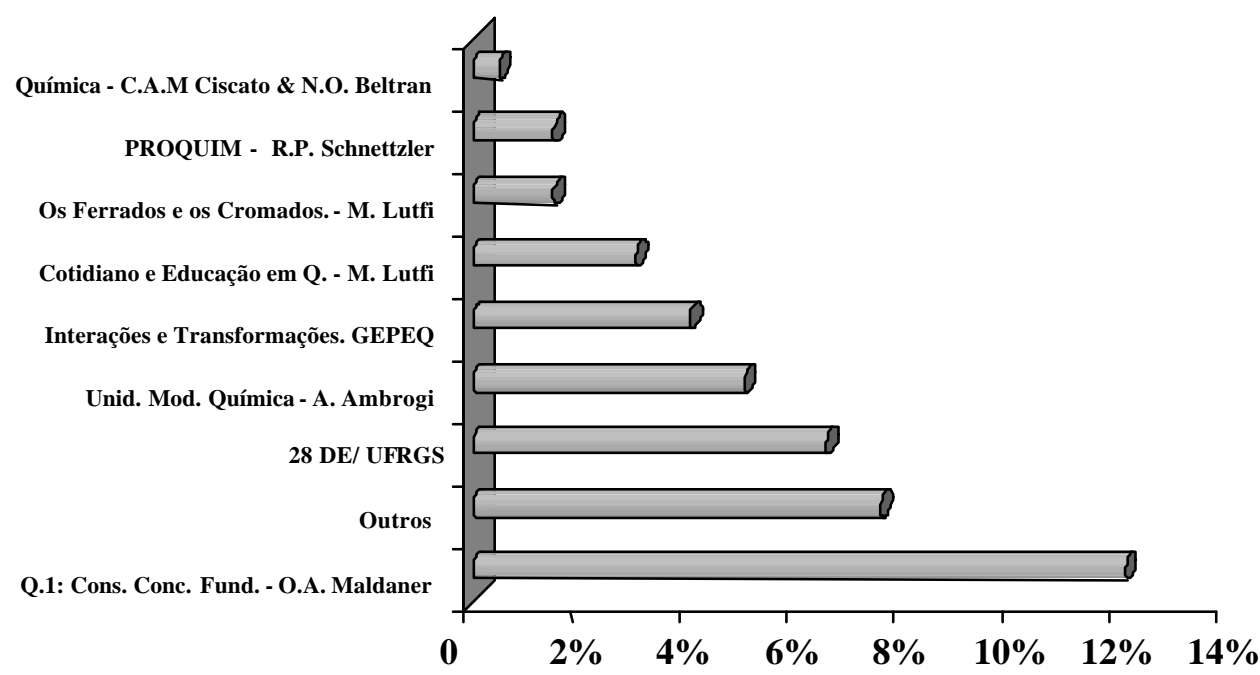

Gráfico 2. Propostas alternativas de ensino de Química conhecidas pelos 198 professores participantes do Curso de Qualificação em Serviço de Professores de Química do RS. ${ }^{23}$ 
diferenciada dos conceitos e suas relações. Essas características dificultam para o professor a análise, pois mais do que buscar obstáculos epistemológicos e recursos que dificultam a aprendizagem, os professores precisam entender a lógica de cada livro. Outra razão para a semelhança nos resultados das análises dos professores é que grande parte desses livros tem, por parte dos autores, um direcionamento para aprendizagem centrado em uma teoria de referência. São livros escritos buscando alternativas didáticas às abordagens comuns de conhecimentos químicos que não estão superando os problemas crônicos desse ensino, portanto possuem no seu fabrico um cuidado com os aspectos que podem impedir a apropriação desse conhecimento.

\section{ALGUMAS CONSIDERAÇÕES FINAIS}

Esse trabalho, que não se encerra nas temáticas desse artigo, mas tem aqui seu início, evidencia a análise dos professores, e que se registre, não evidencia a nossa análise destes livros. Faz-se, outrossim, evidenciar como os professores escolhem, lêem, utilizam e constróem seus currículos com o auxílio destes livros, bem como as dificuldades que encontram de pensar novos critérios e aplicá-los nas suas escolhas.

Destacando a questão dos critérios de análise utilizados pelos professores, pode-se dizer que estão de acordo com a sua realidade imediata e esse é um aspecto bastante positivo. Porém a valorização excessiva do conteúdo e do conhecimento químico é uma questão preocupante. Dado que os principais interesses dos professores são verificar se os livros possuem bastantes exercícios para o vestibular e alguma alusão ao cotidiano dos alunos, o mínimo que se pode inferir é que o conhecimento químico presente nesses livros é tido como certo, definitivo e inquestionável. Cabe perguntar, então, onde estão sendo aplicadas as teorias educacionais baseadas nas obras de Piaget, Ausubel, Vygotsky, Freire, entre outros? Quem utiliza os conhecimentos produzidos na educação química? Se os livros didáticos tradicionais não incluem aspectos relevantes dessas teorias para auxiliar a aprendizagem, fazendo apenas retoques nos textos que são reproduzidos desde a década de 70 e os livros alternativos que trazem algumas inovações nesse sentido não são conhecidos pelos professores, em que momento a academia se aproximou da sala de aula? Qual o alcance das nossas teorizações? Qual a distância entre o conhecimento acadêmico e a prática escolar?

Ademais da questão dos critérios de escolha utilizado pelos professores e complementar a essa, é importante destacar as dificuldades dos docentes frente ao conhecimento químico e educacional. Os professores têm sérias lacunas na sua formação em ambos os aspectos. As controvérsias relativas aos livros analisados possuírem ou não obstáculos epistemológicos é claramente a dificuldade dos professores de entenderem o conceito de obstáculo epistemológico e, mais do que isso, de entenderem o conhecimento químico. Quando Alice Lopes ${ }^{25}$ evidencia um obstáculo substancialista na conceituação do ouro como um metal amarelo, os professores não vêm motivo para considerar esse um obstáculo, pois o ouro visível é amarelo; parecem não perceber que se está discutindo o não visível, trabalhando com uma ciência de modelos e teorias muito diferente do mundo microscópico e macroscópico.

Sabe-se que, com a intensificação do trabalho do professor e as adversidades que tornam os saberes de sua prática difíceis de serem gerenciados, os recursos literários são os refúgios que acabam por definir a ação docente ${ }^{26}$, e percebeu-se, através dessa análise, que esses refúgios são pouco ou nada contestados. A "escolha" de livros limita-se a questões econômicas, práticas e estéticas, enquanto que questões sociais e epistemológicas são desconhecidas e o currículo continua sendo pouco problematizado.

Segundo Gimeno Sacristán ${ }^{26}$, o nível e a qualidade das reflexões dos professores é que permite a possibilidade de que esses intervenham em uns temas ou outros, uma vez que existam canais de participação. Segundo Apple ${ }^{27}$, referindo-se à realidade estadunidense, estima-se que $75 \%$ do tempo dos estudantes de escolas elementares e secundárias em sala de aula, além de $90 \%$ do tempo dedicado aos estudos em casa, é gasto com os materiais apresentados pelos livros didáticos. Estas duas colocações e as dificuldades encontradas pelos professores para analisarem os livros didáticos evidenciam uma problemática na qual se percebe premente a necessidade de dar conta das importantes lacunas na formação dos professores, de qualificar o trabalho docente e a sua capacidade de crítica e de resgatar sua autoridade de intelectual formador.

Talvez as palavras qualificação e crítica já estejam um pouco gastas nos discursos e textos que nos interpelam; talvez seja melhor terminar com as palavras de Larrosa ${ }^{28}$, que evidencia justamente o que é o fazer de um professor e que nos parece, às vezes, quase uma utopia:

"É um fazer que requer humildade e silêncio. Mas também exige audácia e falar, porque para deixar aprender tem-se de eliminar muitos obstáculos. Entre eles a arrogância daqueles que sabem."

\section{REFERÊNCIAS}

1. Lopes, A. R. C.; Livros Didáticos: Obstáculos ao Aprendizado da Química; Dissertação de Mestrado; IESAE; Rio de Janeiro, 1990.

2. Schnetzler, R. P.; Quim. Nova 1981, 4, 6.

3. Guerra, R.; Nova Escola 1989, 28,40.

4. Molina, O.; A Qualidade do Livro Didático; Simpósio sobre o livro didático; São Paulo, 1983.

5. Apple, M.; Trabalho Docente e Textos: Economia Política das Relações de Classe e Gênero em Educação; Artes Médicas, Porto Alegre, 1995.

6. Loguercio, R.; Del Pino, J. C.; Livros Didáticos: Mais que uma simples escolha, uma decisão que pode orientar os trabalhos em sala de aula; Área de Educação Química - UFRGS; Porto Alegre, 1995

7. Entende-se o currículo não como listagem de conteúdos para ser cumprida, mas como práticas reais de sala de aula, com suas escolhas, ênfases e percepções específicas. O currículo faz-se por presenças e ausências de temáticas e por relações entre as pessoas (aluno-professor), sendo, portanto, diversificado e múltiplo para cada sala de aula.

8. Bachelard, G.; A Formação do Espirito Científico; Contraponto, Rio de Janeiro, 1996.

9. Loguercio, R.; Del Pino, J. C.; Samrsla, V. E. E.; TecnoLógica 1998, 2, p.56.

10. Loguercio, R.; Del Pino, J. C.; Samrsla, V. E. E.; ref. 9, p.58.

11. Gimeno Sacristán, J.; O Currículo: uma reflexão sobre a prática; Artes Médicas, Porto Alegre, 1998.

12. Feltre, R.; Fundamentos de Química, v. único. 2. Ed.; Moderna, São Paulo, 1996.

13. Peruzzo, T. M.; Canto, E. D.; Química: na Abordagem do Cotidiano, v. único. 1. Ed.; Moderna, São Paulo, 1996.

14. Reis, M.; Química Integral; v. único. FTD, São Paulo, 1993.

15. Quadros e esquemas incompreensíveis, ilustrações que confundem e poluem as páginas, títulos e subtítulos mal distribuídos e uma desorganização capaz de deixar o leitor perdido são características da poluição visual. (ref. 3, p.40)

16. A intensificação representa uma das formas pelas quais os privilégios dos trabalhadores/as são degradados. (ref. 5, p.39)

17. Obstáculos animistas consistem na associação de fatos com seres animados, em sua maioria o homem, fazendo a vida transcender ao domínio que lhe é próprio. Por obstáculos verbais entende-se o uso indiscriminado de termos da linguagem comum, o que pode não apenas impe- 
dir o domínio do conhecimento científico, como também cristalizar conceitos errados - verdadeiros obstáculos à abstração. Os obstáculos realistas se configuram quando se propõe a investigação científica dentro do concreto, sem evoluir para o abstrato. E por obstáculos substancialistas entende-se a tendência de considerar que as características estão vinculadas à substância somente e não à interação entre substâncias.

18. Experiências ilustrativas se caracterizam por demonstrar na prática o que foi dito em sala de aula, enquanto que experiências investigativas podem proporcionar a elaboração e a aquisição de generalizações através da análise dos resultados experimentais. (ref. 2, p.11)

19. Loguercio, R.; Del Pino, J. C.; Samrsla, V. E. E.; ref. 9, p.61.

20. Maldaner, O. A.; Química 1: Construção de Conceitos Fundamentais; UNIJUI, Ijuí, 1992.

21. Eichler, M.; Barbosa, V.; Del Pino, J. C.; Extensão 1998, $1,29$.

22. Lopes, C. V.; Del Pino, J. C.; Espaços na Escola 1997, $4,43$.

23. Ciscato, C. A M.; Beltran, N. O.; Química; Cortez, São Paulo, 1991. Mazon, A. B.; Rezende, D. B.; Romanelli, L. I.; Marcondes, M. E. R.; Beltran, N. O.; Schenetzler, R. P.; Projeto de ensino de Química para o $2^{\circ}$ Grau; Unicamp, Campinas, 1986. Lutfi, M.; Os ferrados e os cromados: produção social e apropriação privada do conhecimento químico; UNIJUÍ, Ijuí, 1992. Lutfi, M.; Cotidiano e educação em química: os aditivos em alimentos como proposta para o ensino de química no $2^{\circ}$ grau; UNIJUÍ, Ijuí, 1988. GEPEQ; Interações e Transformações: Química para o $2^{\circ}$ Grau: Livro do aluno; Editora da USP, São Paulo, 1993. Ambrogi, A.;
Versolato, E. F.; Lisboa, J. C. F.; Unidades modulares de Química; Hamburg, São Paulo, 1987. Maldaner, O. A.; Química 1: Construção de Conceitos Fundamentais; UNIJUI, Ijuí, 1992.

24. Ciscato, C. A M.; Beltran, N. O.; Química; Cortez, São Paulo, 1991. Lutfi, M.; Os ferrados e os cromados: produção social e apropriação privada do conhecimento químico; UNIJUÍ, Ijuí, 1992. Lutfi, M.; Cotidiano e educação em química: os aditivos em alimentos como proposta para o ensino de química no $2^{\circ}$ grau; UNIJUÍ, Ijuí, 1988. GEPEQ; Interações e Transformações: Química para o $2^{\circ}$ Grau: Livro do aluno; Editora da USP, São Paulo, 1993. GEPEQ; Interações e Transformações: Química para o $2^{\circ}$ Grau: Livro do professor; Editora da USP, São Paulo, 1993. GEPEQ; Interações e Transformações II: Química para o $2^{\circ}$ Grau: Livro do aluno; Editora da USP, São Paulo, 1995. GEPEQ; Interações $e$ Transformações II: Química para o $2^{\circ}$ Grau: Livro do professor; Editora da USP, São Paulo, 1995. Ambrogi, A.; et all; Unidades modulares de química; Hamburg, São Paulo, 1987. Maldaner, O. A.; Química 1: Construção de Conceitos Fundamentais; UNIJUI, Ijuí, 1992. Maldaner, O. A.; Zambiazi, R.; Química I1: Consolidação de Conceitos Fundamentais; UNIJUI, Ijuí, 1993.

25. Lopes, A. R. C., Livros didáticos: obstáculos ao aprendi zado da química. $6^{\circ}$ Encontro Nacional de Ensino de Química. Sociedade Brasileira de Química. São Paulo, 1992.

26. Sacristán, G.; ref. $11,152$.

27. Apple, M.; ref. 5, 85.

28. Larrosa, J. Literatura, Experiências e Formação; in: Costa, M. V.; Caminhos Investigativos; Mediação, Porto Alegre, 1996, 153. 